\title{
Ion Dissociation Dynamics of 1,2,3,4-Tetrahydronaphthalene: Tetralin as \\ a Test Case For Hydrogenated PAHs
}

\author{
Malick Diedhiou, ${ }^{a}$ Brandi J. West, ${ }^{a}$ Jordy Bouwman ${ }^{b}$ and Paul M Mayer ${ }^{a,}{ }^{*}$ \\ a Department of Chemistry and Biomolecular Sciences, University of Ottawa, Ottawa Canada K1N \\ 6N5 \\ b Laboratory for Astrophysics, Leiden Observatory, Leiden University, PO box 9513, 2300RA \\ Leiden, the Netherlands
}

*corresponding author: Paul M Mayer pmmayer@uottawa.ca, 613 562-5800 ext 6038

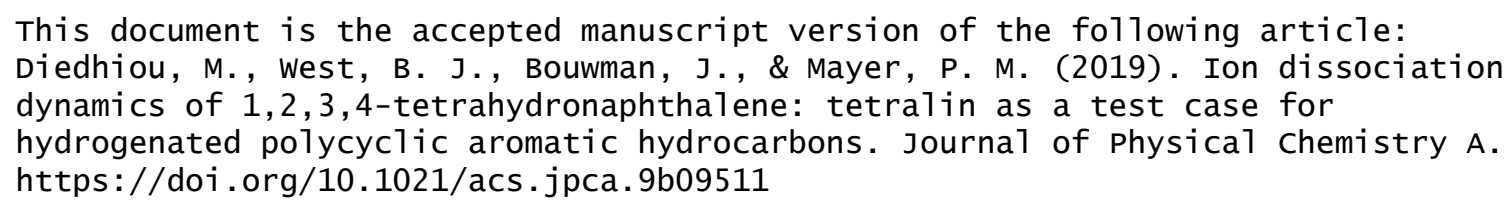




\begin{abstract}
The unimolecular dissociation of ionized tetralin was probed by tandem mass spectrometry, imaging photoelectron photoion coincidence (iPEPICO) spectroscopy and theory. The major reactions observed were the loss of the hydrocarbons $\mathrm{CH}_{3}{ }^{\circ}, \mathrm{C}_{2} \mathrm{H}_{4}$ and $\mathrm{C}_{3} \mathrm{H}_{5}{ }^{\bullet}$ together with $\mathrm{H}^{\bullet}$ atom loss. RRKM modeling of the iPEPICO data suggested a two well potential energy surface. Ionized tetralin can lose all four neutrals via $\mathrm{H}$-shift and ring-opening reactions, or $\mathrm{CH}_{3}{ }^{\circ}$ and $\mathrm{C}_{2} \mathrm{H}_{4}$ after interconversion to the 1-methylindane ion, a process similar to that found for ionized 1,2-dihydronaphthalene (isomerizing to form the 1-methylindene ion structure). This was confirmed at the $B 3 L Y P / 6-31+G(d, p)$ level of theory and potential mechanisms for all reactions are described. The ionization energy of tetralin was established from the threshold photoelectron spectrum to be $8.46 \pm 0.01 \mathrm{eV}$.
\end{abstract}




\section{INTRODUCTION}

Polycyclic aromatic hydrocarbons (PAHs) are a class of organic molecules suggested to constitute roughly $20 \%$ of carbon in the interstellar medium (ISM). ${ }^{1}$ These species exist in both neutral and ionic forms and both are potentially involved in processes such as $\mathrm{H}_{2}$ formation and the shielding of organic chemical reactions from high energy radiation. ${ }^{2}$ PAHs in the ISM can absorb UV light from stars, initiating photodissociation to form important interstellar molecules. Molecular $\mathrm{H}_{2}$ is the most prolific molecular species found in the interstellar medium (ISM). Whereas it has been long recognized that $\mathrm{H}_{2}$ is formed on dust grains, ${ }^{3}$ investigation of the involved mechanisms is still a very active subject of research. ${ }^{4,5}$ One popular theory is that polycyclic aromatic hydrocarbons (PAH) may play a role in the formation of $\mathrm{H}_{2}$ by acting as catalysts. ${ }^{1}$ Atomic hydrogen would adsorb onto the surface of the molecules, thus hydrogenating the PAHs, prior to desorption of $\mathrm{H}_{2}{ }^{6-11}$ This reaction demonstrates the importance of investigating the energetics of not only PAHs but modified PAHs as well, such as hydrogenated species.

There has been very little work done on superhydrogenated PAHs. A theoretical study was conducted on protonated naphthalene which had the $\mathrm{H}^{\bullet}$ loss at an activation energy of $2.71 \mathrm{eV}$ which is in good agreement with that for $\mathrm{H}^{\bullet}$ loss from dihydronaphthalene. ${ }^{12}$ Reitsma et al. have also shown the effect of hydrogenation on coronene using soft x-ray spectroscopy; they showed that hydrogenation under these high energy conditions acts as a protector for the carbon backbone. ${ }^{13}$ The opposite was observed for ionized hydrogenated pyrene studied at high energy collision-induced dissociation (CID) mass spectrometry and action spectroscopy. Here, it was observed that the appearance energy for $\mathrm{CH}_{3}{ }^{\circ}$-loss decreased with increasing hydrogenation. ${ }^{14-}$ 16 Hydrogenation of coronene has been explored. ${ }^{17-19}$ We previously studied 1,2- 
dihydronapthalene and 9,10-dihydrophenanthrene by the imaging photoelectron photoion coincidence (iPEPICO) technique. ${ }^{20}$ Unlike PAH ions, which display unimolecular losses of $\mathrm{H}^{\bullet}$ (both directly and sequentially) and acetylene, the two dihydroPAH ions undergo reactions leading to loss of $\mathrm{H}^{\bullet}$ and $\mathrm{CH}_{3}$. Both were found to isomerize to a methylindene analogue at low internal energies, allowing for $\mathrm{H}^{\bullet}$ and $\mathrm{CH}_{3}{ }^{\circ}$-loss, but as internal energy increases this channel was outcompeted by direct $\mathrm{H}^{\bullet}$-loss from the molecular ion. $\mathrm{No}_{2}$ was formed in the decomposition of these ions.

In light of the results for dihydroPAH ions, we have examined the unimolecular reactions of ionized 1,2,3,4-tetrahydronaphthalene, or tetralin, by iPEPICO spectroscopy and tandem mass spectrometry to explore the possibility of $\mathrm{H}_{2}$ formation from polyhydrogenated precursors. Tetralin, with chemical formula $\mathrm{C}_{10} \mathrm{H}_{12}$, is one of the smallest superhydrogenated PAHs and is a component of jet ${ }^{21}$ and diese $\left.\right|^{22}$ fuels. The unimolecular decomposition of neutral tetralin was previously studied at high temperature under single-pulse shock-tube conditions (1000-1400K) by Tsang and $\mathrm{Cui}^{23}$ who determined rates for channels resulting in the formation of ethylene + benzocyclobutene and $o$-allyltoluene. Tetralin is also an intermediate in the synthesis of agricultural chemicals and a good hydrogen donor in the fuel cells. ${ }^{24-26}$ So, the question arises if it can be a hydrogen donor in the ISM.

\section{EXPERIMENTAL METHODS}

\section{TANDEM MASS SPECTROMETRY}

Atmospheric pressure chemical ionization (APCl) experiments were performed on a Micromass Quattro Ultima (Waters Micromass, Manchester, U.K.) triple quadrupole mass spectrometer 
equipped with a Z-spray source. Tetralin was purchased from Sigma-Aldrich (Sigma-Aldrich, Oakville, ON, CA, >97\% purity) and used without further purification. Compounds were dissolved in chlorobenzene to produce a $100 \mu \mathrm{g} \mathrm{mL} \mathrm{L}^{-1}$ solution. ${ }^{27}$ This solution was delivered to the APCI source by syringe pump at a flow rate of $50 \mu \mathrm{Lmin}^{-1}$. The source block and probe temperatures were $80^{\circ} \mathrm{C}$ and $400{ }^{\circ} \mathrm{C}$, respectively, while the corona and cone voltages were $4.0 \mathrm{kV}$ and $40 \mathrm{~V}$. The quadrupole resolution was set to 18 in the Masslynx software to provide baseline separation of all peaks, resulting in a mass resolution $(\mathrm{m} / \Delta \mathrm{m})$ of 100 . Collision-induced dissociation (CID) was carried out using argon collision gas at a pressure of approximately $7.8 \times 10^{-4} \mathrm{mbar}$ over a laboratory-frame collision energy $\left(E_{\text {lab }}\right)$ range of 0 to $31 \mathrm{eV}$.

\section{IMAGING PHOTOELECTRON PHOTOION COINCIDENCE SPECTROSCOPY (IPEPICO)}

iPEPICO spectroscopy experiments were conducted on the VUV beamline at the Swiss Light Source (SLS, Paul Scherrer Institut, Villigen, Switzerland) and have been described in detail elsewhere and only a brief description will be provided here..$^{28-30}$

Tetralin was thermally volatilized at $25^{\circ} \mathrm{C}$ into the photon interaction region with a heated oven and photoionized by monochromatic synchrotron radiation (4-8 meV resolution depending on the photon energy). ${ }^{31}$ Photoions and photoelectrons are extracted using a weak electric field of $218 \mathrm{~V} / \mathrm{cm}$. The photoions are accelerated toward a time-of-flight (TOF) mass spectrometer, while the ejected electrons are velocity-mapped on an imaging RoentDek delay line detector. The electrons are time- and position-stamped at the detector and the corresponding photoions are detected in delayed coincidence. Threshold electrons account for the majority of the signal at the center of the multichannel plate, MCP, detector whereas non-zero-kinetic energy electrons are 
mostly detected according to their off-axis momentum. Some of the non-zero-kinetic energy electrons will have the proper trajectory to hit the center spot, therefore the mass spectrum based on electrons detected in a ring around the center spot is used to account for this 'hot electron' contamination. The ions detected in coincidence with electrons arriving in the ring can then be subtracted from ions detected in coincidence with the electrons that appeared in the center to obtain the threshold photoionization mass spectrum. ${ }^{32}$ Photoions are space-focussed onto the detector, resulting in a mass resolution of $\Delta \mathrm{m} / \mathrm{m}=270$. The photon energy range used for the photoelectron spectrum was $8.3-15.5 \mathrm{eV}$, with data points taken every $0.05 \mathrm{eV}$. Longer accumulation times were used for points between 10 and $13.5 \mathrm{eV}$ for the breakdown diagram measurement.

The TOF mass spectrometer consists of two acceleration regions, one with a low draw out potential that allows ions dissociating on the microsecond time scale to do so while being accelerated. This results in asymmetric time-of-flight peaks for product ions that form from the parent ion that dissociates as it propagates down the flight tube, which can be modeled to extract unimolecular decay rate constants as a function of photon energy. When multiple product ions are generated, they are all formed with the same overall effective decomposition rate constant of the precursor ion, and the fractional fragment ion abundances, i.e., the branching ratios, can be used to apportion absolute dissociation rates to each of the decay channels. This way, dissociation rate constants are obtained for all channels on the basis of the asymmetric peak profile of just one fragment ion. 


\section{COMPUTATIONAL METHODS}

Geometry optimizations and harmonic vibrational frequency calculations of all species and transition states were conducted using the Gaussian 16 package ${ }^{33}$ at the B3LYP/6-31+G(d,p) level of theory. Transition states were confirmed with the intrinsic reaction coordinate (IRC) protocol. Franck-Condon simulations utilized the double harmonic approximation. ${ }^{34}$ Molecular orbital energies were calculated using the Outer Valence Green's Function Method at the OVGF/cc-pVTZ level of theory.

The minimaIPEPICO program was used to fit the iPEPICO breakdown distributions. ${ }^{29}$ The program combines the physical parameters of the iPEPICO experimental set up with temperature (for the initial neutral molecule internal energy distribution) and the rate constant for each pathway to calculate theoretical branching ratios for the ion dissociation as a function of photon energy, which are then compared to the experimental breakdown curves. Rice-RamspergerKassel-Marcus (RRKM) theory was used to calculate $k(E)$ according to equation $1,{ }^{35,36}$

$k(E)=\frac{\sigma N^{\ddagger}\left(E-E_{0}\right)}{h \rho(E)}$

where $\sigma$ represents the reaction degeneracy, $h$ is Planck's constant, $N^{\ddagger}\left(E-E_{0}\right)$ is the number of internal states for the transition state at internal energy $\left(E-E_{0}\right)$ and $\rho(E)$ is the density of states for the reactant ion at internal energy $(E)$, and $E_{0}$ is the reaction activation energy at $0 \mathrm{~K}$. For tetralin, a $\sigma$ value of 4 was used for $\mathrm{H}^{\bullet}$-loss corresponding to the hydrogens bound to the four $\mathrm{sp}^{3}$ carbon atoms, each $\mathrm{CH}_{3}{ }^{\circ}$-loss was assigned a value of $1, \mathrm{C}_{2} \mathrm{H}_{4}$ loss from the molecular ion was assigned $\sigma=2$, while that from the isomer (see modeling) was assumed to be 1 and $\sigma$ for $\mathrm{C}_{3} \mathrm{H}_{5}{ }^{\circ}$ loss was assigned a value of 1 . Rotational-vibrational densities and sums-of-states were calculated using $B 3 L Y P / 6-31+G(d, p)$ rotational constants and harmonic vibrational frequencies 
by the direct count algorithm of Beyer and Swinehart. ${ }^{37}$ The numbers of internal states for the transition state for the reactions were approximated using the vibrational frequencies and rotational constants of the precursor ion, less one vibrational mode to represent the reaction coordinate. Of the remaining $3 \mathrm{~N}-7(\mathrm{~N}=$ number of atoms) modes for the transition state, the lowest five frequencies were scaled to adjust the entropy of activation, $\Delta^{\ddagger} S$. Frequency multiplication factors less than one increase $\Delta^{\ddagger} S$ while values greater than one decrease $\Delta^{\ddagger} S .{ }^{35}$ The agreement between the experimental and theoretical breakdown curves was achieved by varying $E_{0}$ and $\Delta^{\ddagger} S$. Error bars were established by finding the limits in $E_{0}$ and $\Delta^{\ddagger} S$ that resulted in a value of $<5 \%$ for equation 2 :

Difference $=1-\frac{\Sigma((\text { Expt })(\text { Calc }))}{\sqrt{\left(\sum((\text { Expt })(\text { Expt })) \Sigma((\text { Calc })(\text { Calc }))\right)}}$

where Expt and Calc refer to the experimental and calculated relative ion abundances in the breakdown curves, respectively.

\section{RESULTS AND DISCUSSION}

\section{THRESHOLD PHOTOELECTRON SPECTRUM}

The mass-selected threshold photoelectron spectrum (TPES) of tetralin was acquired from 8.3 $15.5 \mathrm{eV}$ with steps of $0.001 \mathrm{eV}$ to establish the ionization energy, Fig. 1. The TPES exhibits a sharp first ionization band from which an ionization energy (IE) value of $8.46 \pm 0.01 \mathrm{eV}$ is derived. A simulated ionization spectrum is constructed using the program ezspectrum by considering the overlap between the vibrational wavefunctions in the ground state neutral tetralin with those in the ground state of the cation. The simulated spectrum is shown in the inset in Fig. 1 both as a stick diagram as well as a spectrum that results from a convolution of the stick diagram with 
Gaussian shape with a Full-Width-at-Half-Maximum of $30 \mathrm{meV}\left(250 \mathrm{~cm}^{-1}\right)$. All of the main vibronic resonances observed in the experimental spectrum are accounted for by the simulations. There is a qualitative mismatch between the measured and simulated spectrum starting at an energy of $8.6 \mathrm{eV}$ which is due to an electronically-excited state in the tetralin cation. OVGF calculations were used to locate tetralin ion excited states and the results are overlaid on the TPES in Fig.1. Molecular orbital 17 produces an excited state that overlaps the ground state vibrational progression around $8.7 \mathrm{eV}$, causing the aforementioned mismatch. Tabulated molecular orbital vertical ionization energies can be found in Table S1 of supporting information.

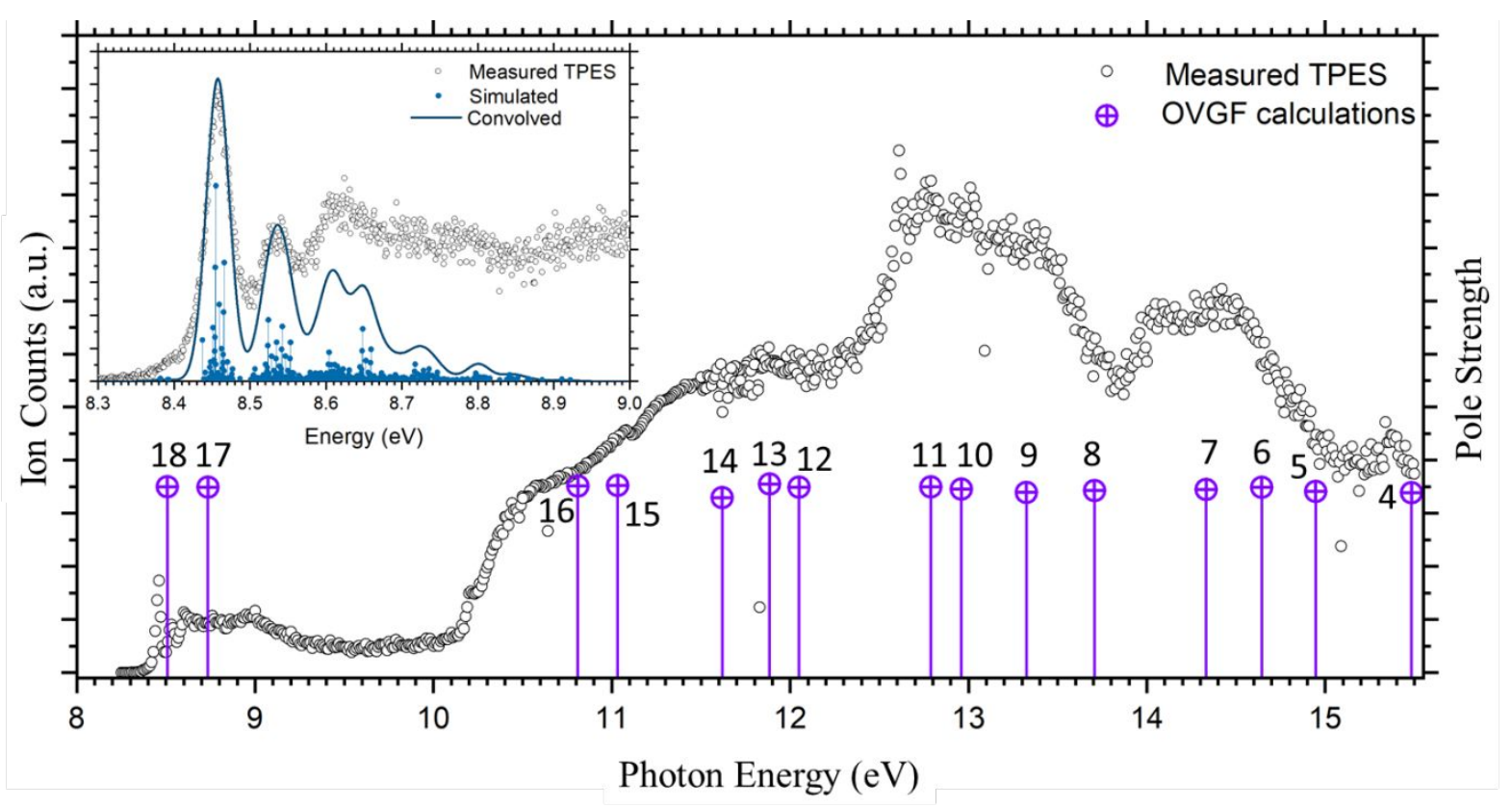

Figure 1: Overview of the TPES of tetralin to $16 \mathrm{eV}$, with OVGF results. The inset holds an expansion of the threshold region together with a Franck-Condon simulated spectrum. The simulated spectrum is displayed both as a stick diagram, as well as a spectrum that results from a convolution of the stick spectrum with a 30 meV FWHM Gaussian line shape. 


\section{COLLISION-INDUCED DISSOCIATION (CID)}

The CID breakdown graph for ionized tetralin is shown in Fig. 2.

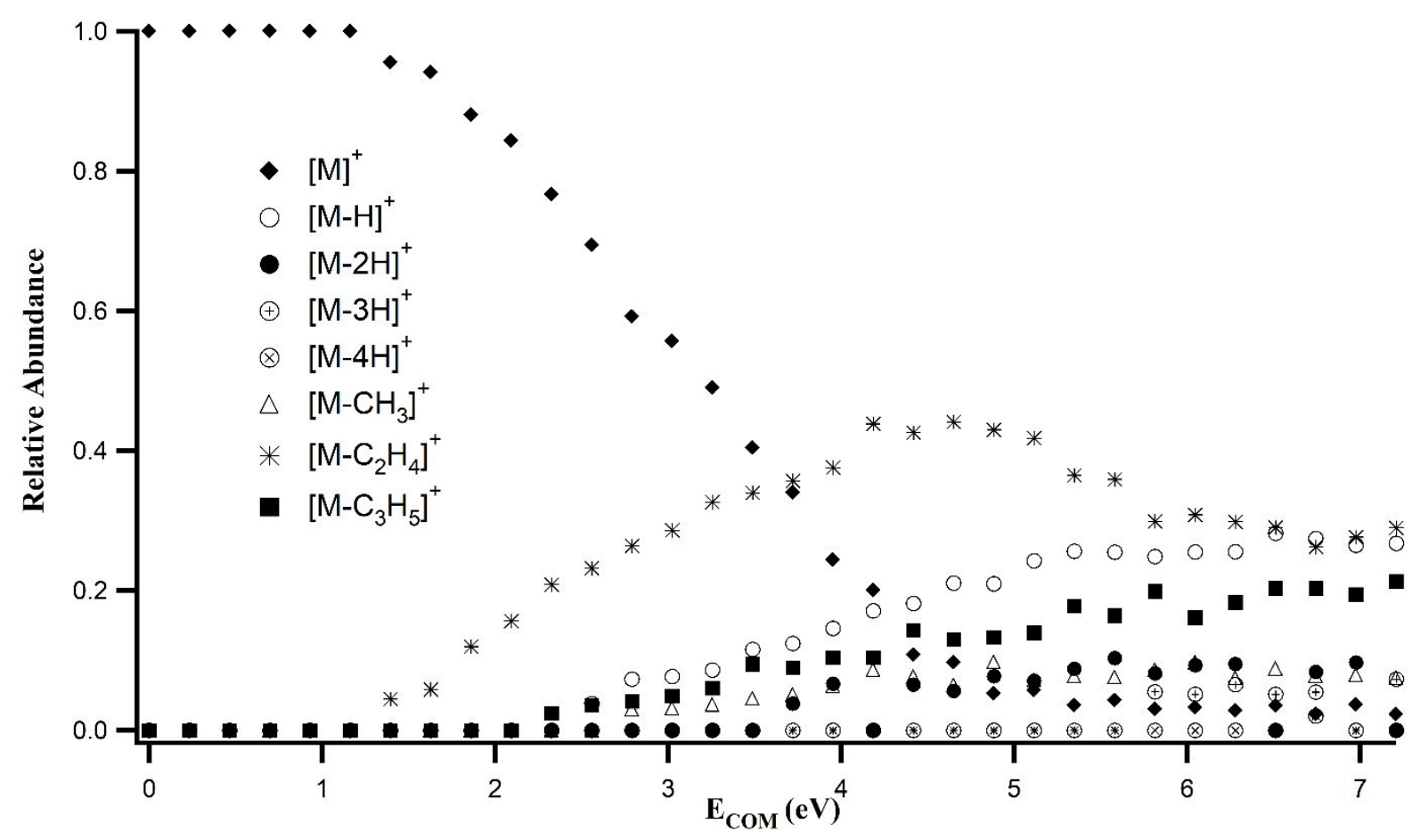

Figure 2. CID breakdown graph for ionized tetralin.

The decomposition of tetralin leads to loss of hydrogen atoms (sequential loss of up to $4 \mathrm{H}$ atoms) and hydrocarbon units $\left(\mathrm{CH}_{3}{ }^{\circ}, \mathrm{C}_{2} \mathrm{H}_{4}\right.$ and $\left.\mathrm{C}_{3} \mathrm{H}_{5}{ }^{\circ}\right)$; however, the most significant process are loss of $\mathrm{H}^{\circ}, \mathrm{CH}_{3}{ }^{\circ}, \mathrm{C}_{2} \mathrm{H}_{4}$ and $\mathrm{C}_{3} \mathrm{H}_{5}{ }^{\circ}$ (reactions $\mathrm{R} 1-\mathrm{R} 4$ ), the others accounting for less than $10 \%$ of the total fragmentation at high collision energy (and of this $-2 \mathrm{H}$ is the predominant process).

$$
\begin{aligned}
& \mathrm{C}_{10} \mathrm{H}_{12}{ }^{\cdot+} \rightarrow \mathrm{C}_{10} \mathrm{H}_{11}{ }^{+}+\mathrm{H}^{\bullet} \quad(m / z \text { 131) } \\
& \mathrm{C}_{10} \mathrm{H}_{12}{ }^{\bullet+} \rightarrow \mathrm{C}_{9} \mathrm{H}_{9}{ }^{\bullet+}+\mathrm{CH}_{3} \cdot(m / z \text { 117) } \\
& \mathrm{C}_{10} \mathrm{H}_{12}{ }^{\bullet+} \rightarrow \mathrm{C}_{8} \mathrm{H}_{8}{ }^{\cdot+}+\mathrm{C}_{2} \mathrm{H}_{4}(\mathrm{~m} / z \text { 104) }
\end{aligned}
$$


$\mathrm{C}_{10} \mathrm{H}_{12}{ }^{\circ+} \rightarrow \mathrm{C}_{7} \mathrm{H}_{7}{ }^{+}+\mathrm{C}_{3} \mathrm{H}_{5} \cdot(m / z$ 91)

Based on the sequential appearance of the $-\mathrm{H}^{\bullet}$ and $-2 \mathrm{H}^{\bullet}$ peaks in the breakdown graph, we conclude that $[\mathrm{M}-2 \mathrm{H}]^{\bullet+}$ is due to a step-wise loss of two $\mathrm{H}$ atoms rather than loss of $\mathrm{H}_{2}$.

\section{VUV-INDUCED DISSOCIATION}

The major fragmentation pathways R1-R4 are also observed in the iPEPICO data (Fig. 3a), with the addition of a small peak with $\mathrm{m} / \mathrm{z} 128$ that can only be due to loss of $4 \mathrm{H}^{\bullet}$-atoms, presumably leading to ionized naphthalene (see expanded region in Fig. S1, Supporting Information). Originally thought to be an artifact, this ion is reproducible and is also observed in the $70 \mathrm{eV}$ electron ionization mass spectrum of tetralin. ${ }^{38}$ The lack of this peak in the CID mass spectra, except at high collision energy after loss of three $\mathrm{H}$ atoms, enforces the idea that this channel in the iPEPICO experiment is possibly from a non-statistical process of the molecular ion (vide infra).

The assumption that unimolecular reactions are driven by statistical dynamics is at the heart of transition state theory. So, to model the iPEPICO breakdown curves, we first removed this minor $[\mathrm{M}-4 \mathrm{H}]^{\bullet+}$ peak (Fig. 3b). Representative time-of-flight distributions are shown in Fig. 3c. 

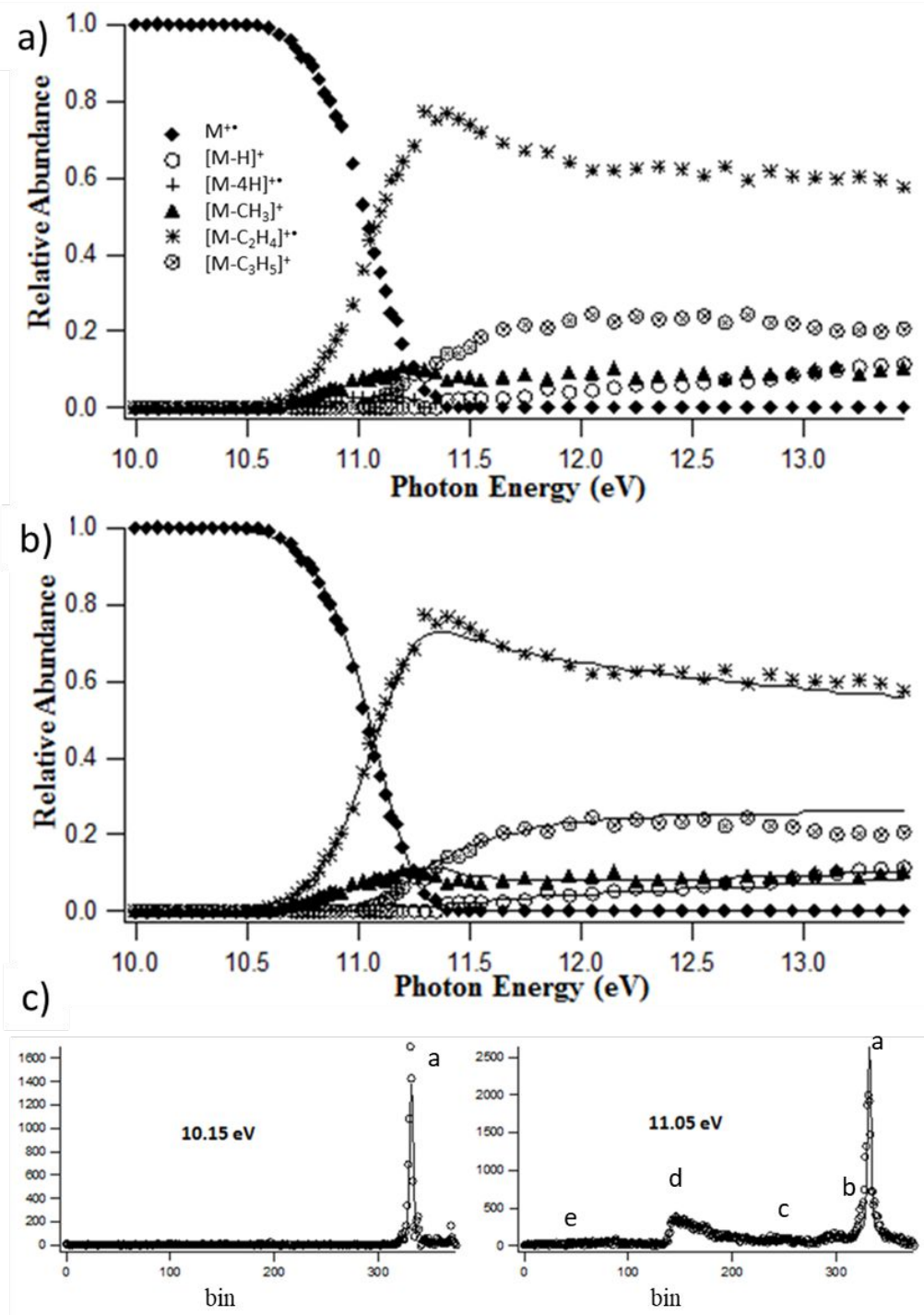
a) $\mathrm{M}^{+}$
b) $[\mathrm{M}-\mathrm{H}]^{+}$
c) $\left[\mathrm{M}-\mathrm{CH}_{3}\right]^{+}$
d) $\left[\mathrm{M}-\mathrm{C}_{2} \mathrm{H}_{4}\right]^{+*}$
e) $\left[\mathrm{M}-\mathrm{C}_{3} \mathrm{H}_{5}\right]^{+}$
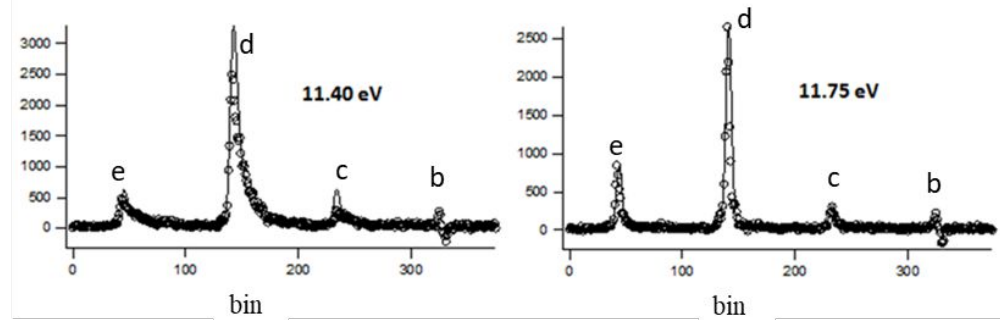

Figure 3a) iPEPICO breakdown diagram of tetralin with $4 \mathrm{H}^{\bullet}-$ loss, b) RRKM (solid line) modeled iPEPICO breakdown curves $\left([\mathrm{M}-4 \mathrm{H}]^{\bullet+}\right.$ ion removed), c) asymmetric time-of-flight distributions (with RRKM fit) at four representative photon energies. "Bin" refers to the multichannel analyzer bin number (related to the time-of-flight). The $y$-axis are count numbers. 


\section{RRKM MODELING}

RRKM modeling of the curves in Fig. 3b,c (solid lines through the experimental points) could only be achieved by assuming a 2-well potential energy surface. This type of surface is consistent with what was required in the case of dihydronaphthalene and dihydrophenanthrene as methyl loss in those two cases required isomerization of the molecular ions to methylindene ions (and its analogue for dihydrophenanthrene). ${ }^{20}$ In addition, it was clear that there had to be two distinct sources for $\left[\mathrm{M}-\mathrm{C}_{2} \mathrm{H}_{4}\right]^{\bullet+}$ and $\left[\mathrm{M}-\mathrm{CH}_{3}{ }^{\circ}\right]^{+}$, and so the resulting, experimentally derived surface is shown in Fig. 4. The isomerization barrier governs the branching ratio between the two pathways

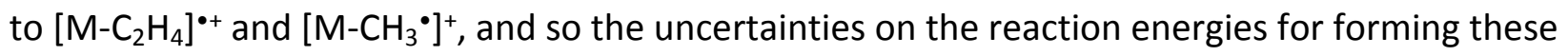
products from the isomer will be significant.

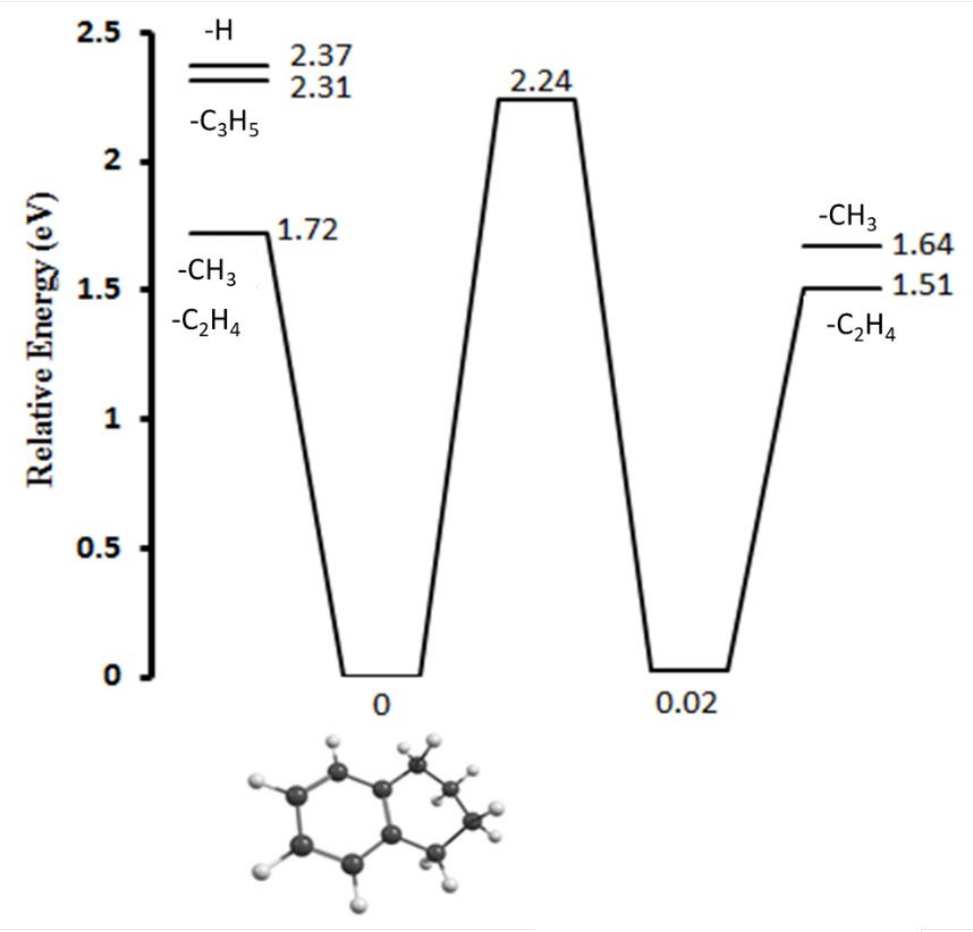


Figure 4. Two-well reaction model used for the RRKM fit to the experimental data. All energies obtained from the fitting procedure.

\section{COMPUTATIONAL RESULTS}

$\mathrm{CH}_{3}{ }^{\circ}$-loss. The most logical source for methyl radical loss is from methylindane (1a, Figure 5), analogous to the loss of $\mathrm{CH}_{3}{ }^{\bullet}$ from methylindene in the case of dihydronaphthalene. ${ }^{20}$ We found a direct isomerization pathway from ionized tetralin (1) to 1-methylindane (1a), which then leads to the loss of a methyl radical (Figure 5). Both the isomerization energy of $2.45 \mathrm{eV}$ and bond cleavage energy of $1.25 \mathrm{eV}$ are consistent with those derived from the RRKM fitting of the iPEPICO data (2.24 and $1.64 \mathrm{eV}$, respectively, given the expected high uncertainty in the latter quantity). 

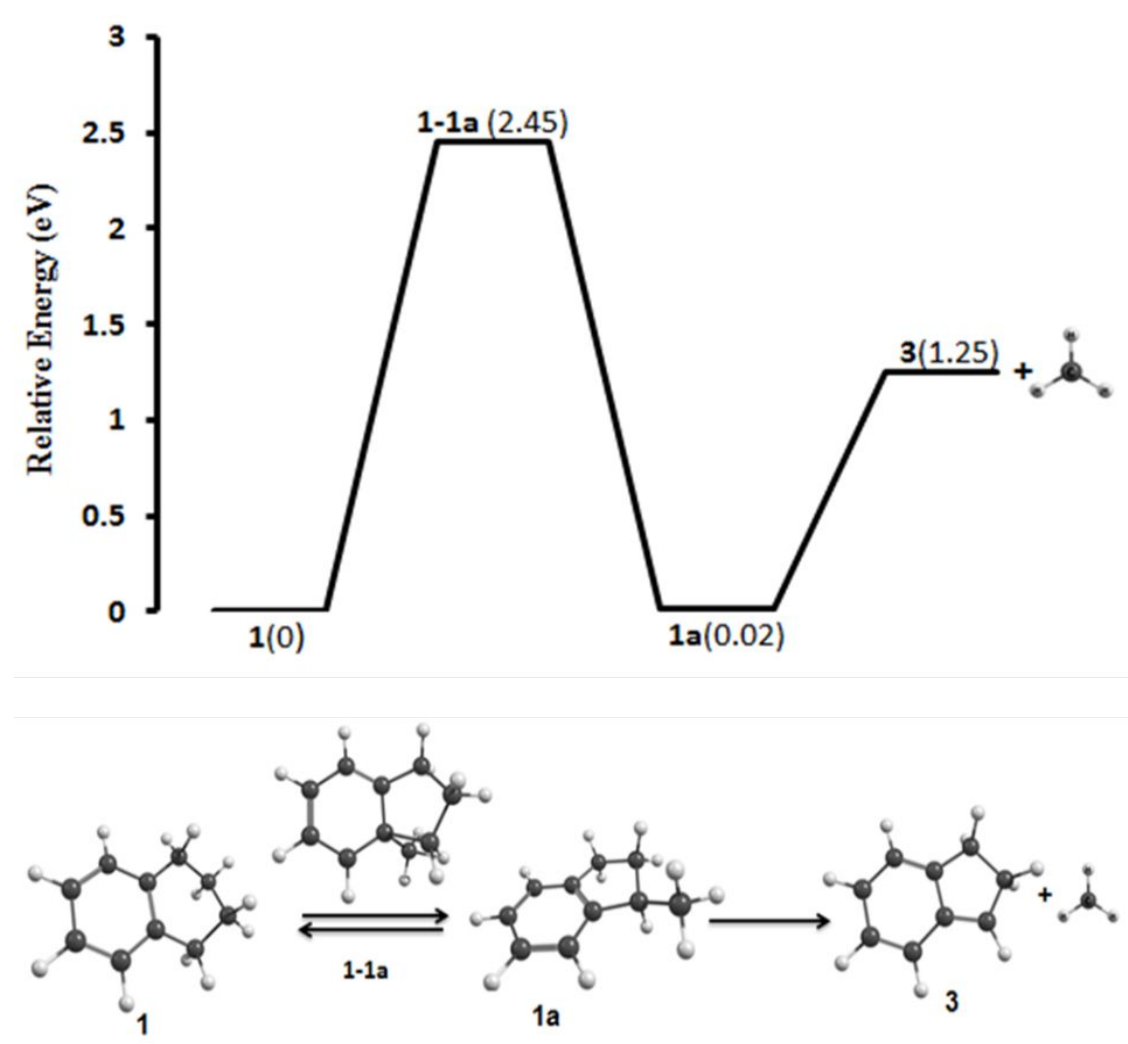

Figure 5. Potential energy surfaces for $\mathrm{CH}_{3}{ }^{\bullet}$-loss from ionized tetralin via 1-methylindane computed at the $B 3 L Y P / 6-31+G(d, p)$ level of theory. Relative energies $(e V)$ quoted in parentheses.

Methyl-loss directly from the tetralin molecular ion (1), without going through the methylindane ion 1a, can occur via the pathway described in Fig. 6. It involves hydrogen migration prior to ring opening to form 1d. Hydrogen migration in the newly-formed side chain can lead to the formation of allyl benzene (4). 

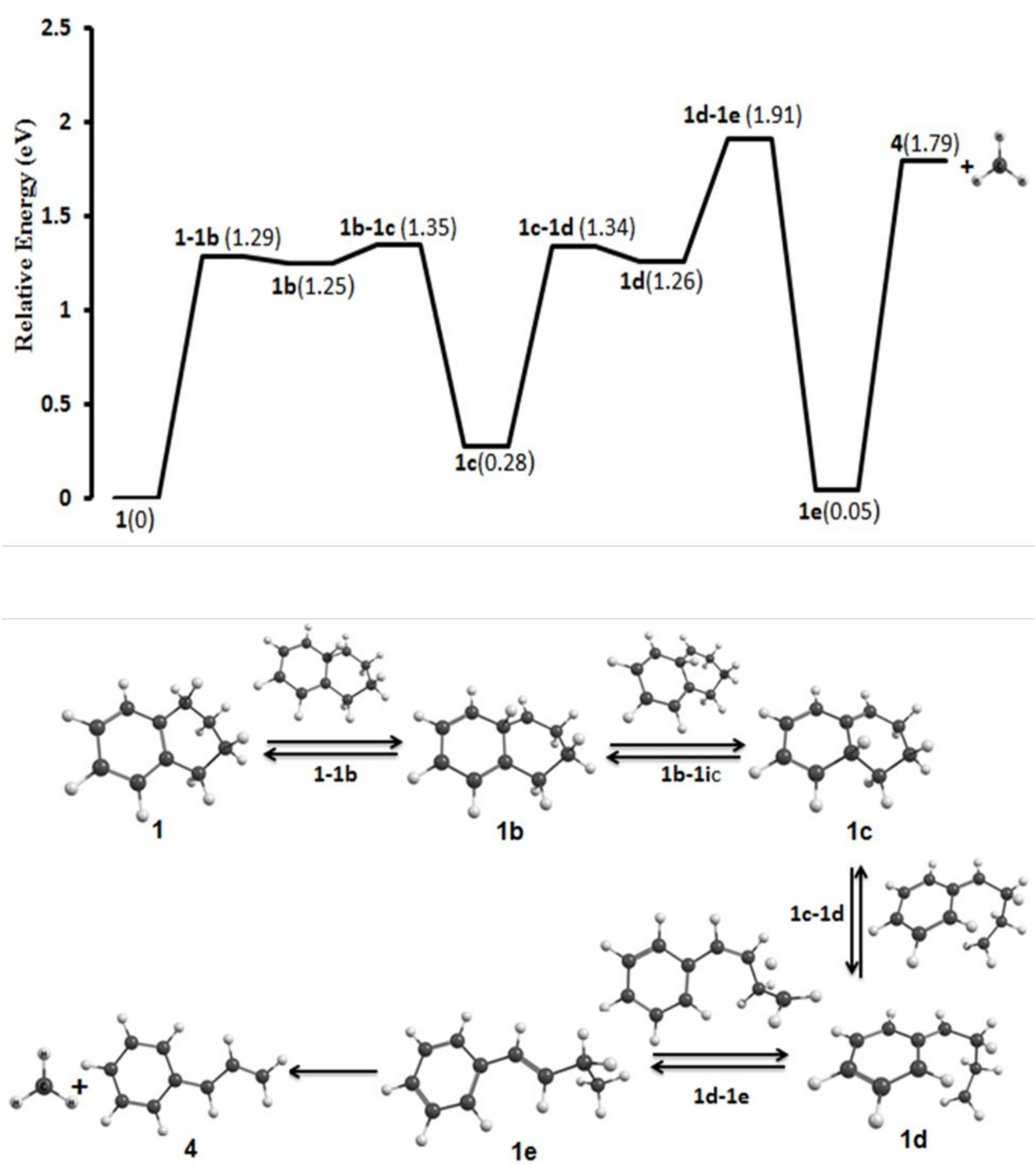

Figure 6. Potential energy surfaces for $\mathrm{CH}_{3}{ }^{-}$-loss from ionized tetralin without participation of methylindane $1 \mathrm{a}$, computed at the $\mathrm{B} 3 \mathrm{LYP} / 6-31+\mathrm{G}(\mathrm{d}, \mathrm{p})$ level of theory. Relative energies $(\mathrm{eV})$ quoted in parentheses.

$\mathrm{C}_{2} \mathbf{H}_{4}$-loss. Unlike PAH ions which lose $\mathrm{C}_{2} \mathrm{H}_{2},{ }^{39,40}$ and dihydroPAH ions which do not exhibit a 2carbon loss channel, ${ }^{20}$ tetralin starts to behave more like a regular hydrocarbon and loses $\mathrm{C}_{2} \mathrm{H}_{4}{ }^{38}$ 
It does so in two distinct channels, one from the molecular ion 1 and one from the 1methylindane isomer 1a. A mechanism for $\mathrm{C}_{2} \mathrm{H}_{4}$-loss from the molecular ion is shown in Fig. 7 and the energy required to generate the ethenylbenzene radical cation $\mathbf{5}$ is $1.40 \mathrm{eV}$. The key intermediate in this reaction, $\mathbf{1} \mathbf{i}$, is formed by hydrogen migration to the opposite bridging carbon. 

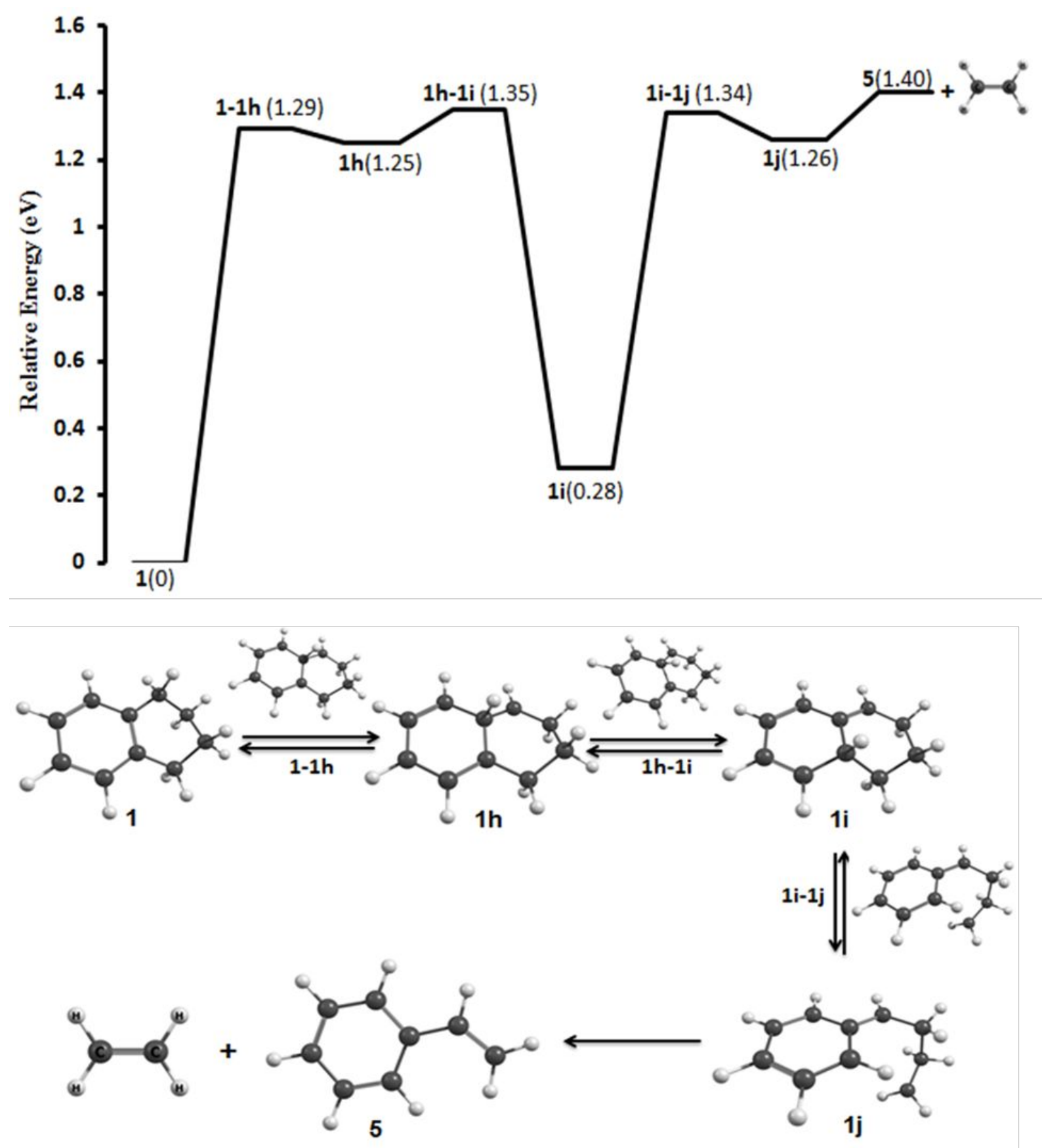

Figure 7. Route for $\mathrm{C}_{2} \mathrm{H}_{4}$-loss from ionized tetralin $\mathbf{1}$ (without the participation of methylindane 1a) at the $B 3 L Y P / 6-31+G(d, p)$ level of theory. Relative energies $(e V)$ quoted in parentheses. Structures $1-1 \mathrm{~h}$ and $\mathbf{1 h}$ differ in the angle of the hydrogen atom on the bridging carbon. 
$\mathrm{C}_{2} \mathrm{H}_{4}$-loss from the 1-methylindane ion (1a in Figure 8) also generates ionized ethenylbenzene 5 but requires $1.99 \mathrm{eV}$ (Fig. 8). This pathway is formed via a ring-opening reaction on the hydrated ring. Given the high energy of TS(1q-1r), it would at best be a minor contributor to the $\mathrm{C}_{2} \mathrm{H}_{4}$-loss channel.
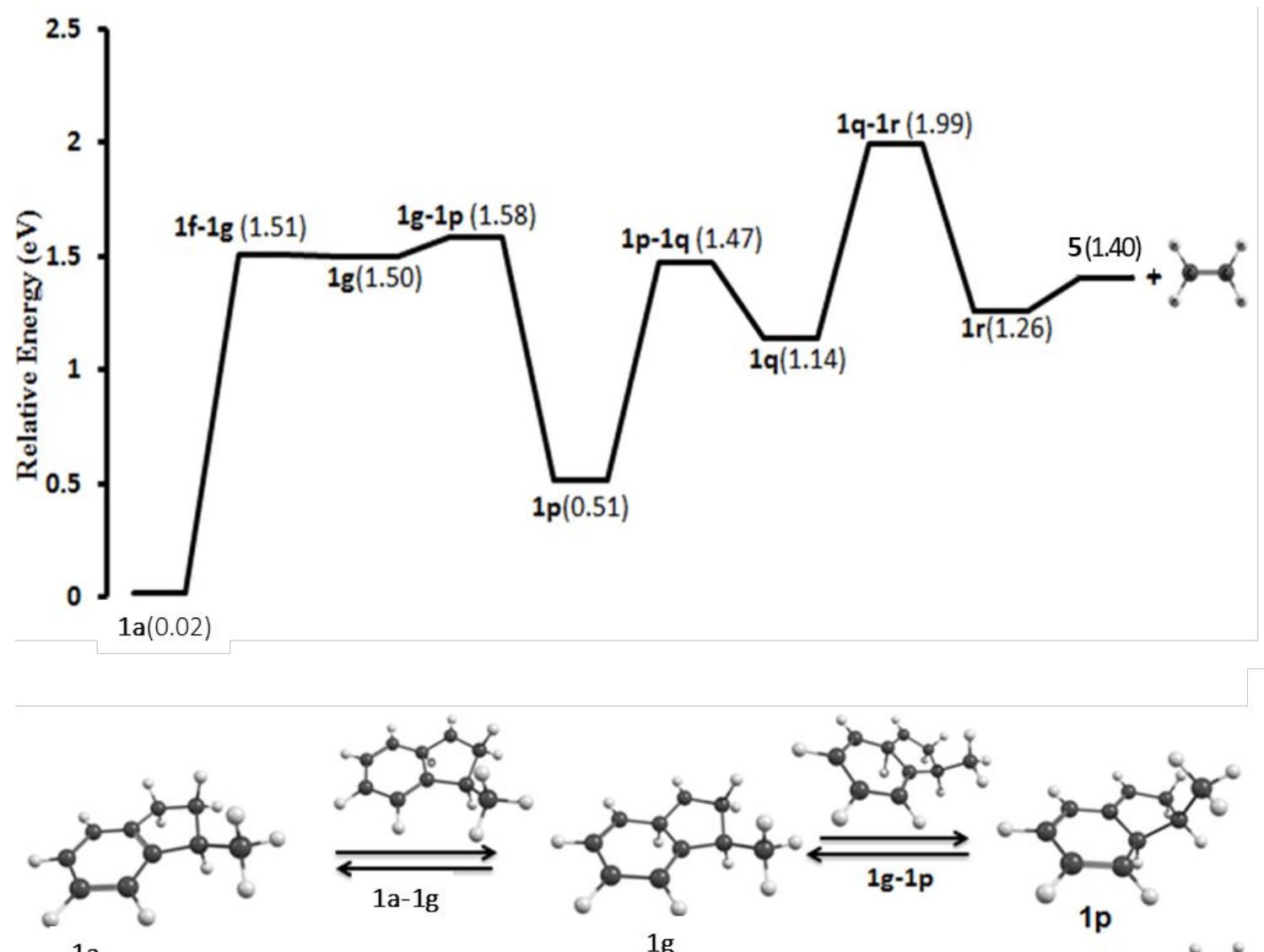

$1 \mathrm{a}$

$1 \mathrm{~g}$

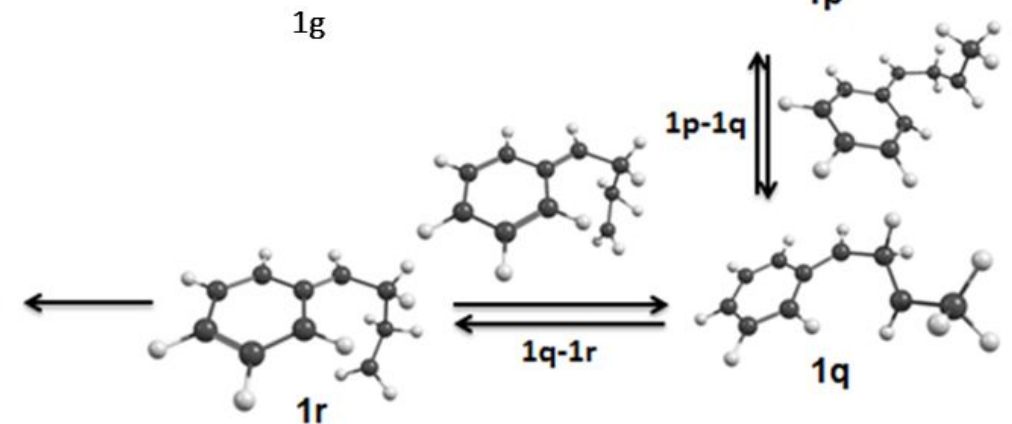

Figure 8. Pathway for $\mathrm{C}_{2} \mathrm{H}_{4}$-loss from ionized 1-methylindane (calculated at the B3LYP/6$31+G(d, p)$ level of theory). Relative energies $(e V)$ quoted in parentheses. 
Unlike napthalene ions, ${ }^{41}$ it does not appear necessary to go through a partially hydrogenated azulene intermediate and form a dihydropentalene isomer. Three key intermediates for such a process lie 2.07, 2.01 and $2.68 \mathrm{eV}$ relative to the tetralin ion (see Figure S2 in Supporting Information).

$\mathrm{C}_{3} \mathrm{H}_{5}{ }^{-}$-loss. Two possible channels leading to the loss of the allyl radical exist. First, the loss of the allyl radical to generate the tropylium ion (6), the lowest energy product ion, is shown in Fig. 9. The highest barrier on this surface has an energy of $2.72 \mathrm{eV}$, significantly higher than the $2.31 \mathrm{eV}$ derived from the RRKM model. Secondly, formation of the benzyl cation (7) requires only 2.10 eV (Fig. 10), which is more consistent with the experimentally-derived value, and so this could be a case that the thermodynamically-most favoured product is not the kinetically-favoured one. 

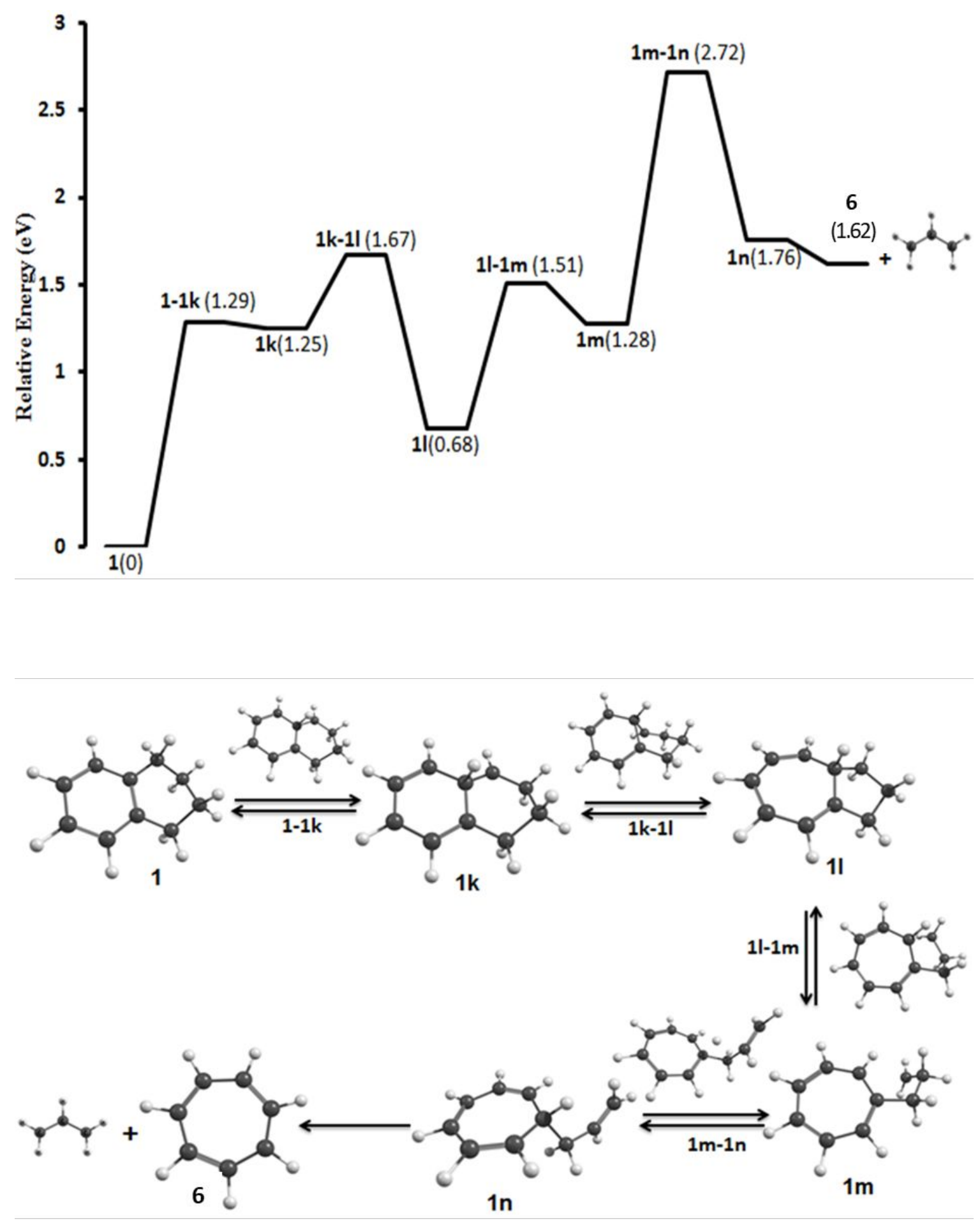

Figure 9. Potential energy surfaces for $\mathrm{C}_{3} \mathrm{H}_{5}{ }^{\circ}$-loss to form the tropylium ion 6 from ionized tetralin, computed at the B3LYP/6-31+G(d,p) level of theory. There must be a barrier between $1 \mathrm{n}$ and 
products, but we were unable to optimize this structure. Relative energies (eV) quoted in parentheses.
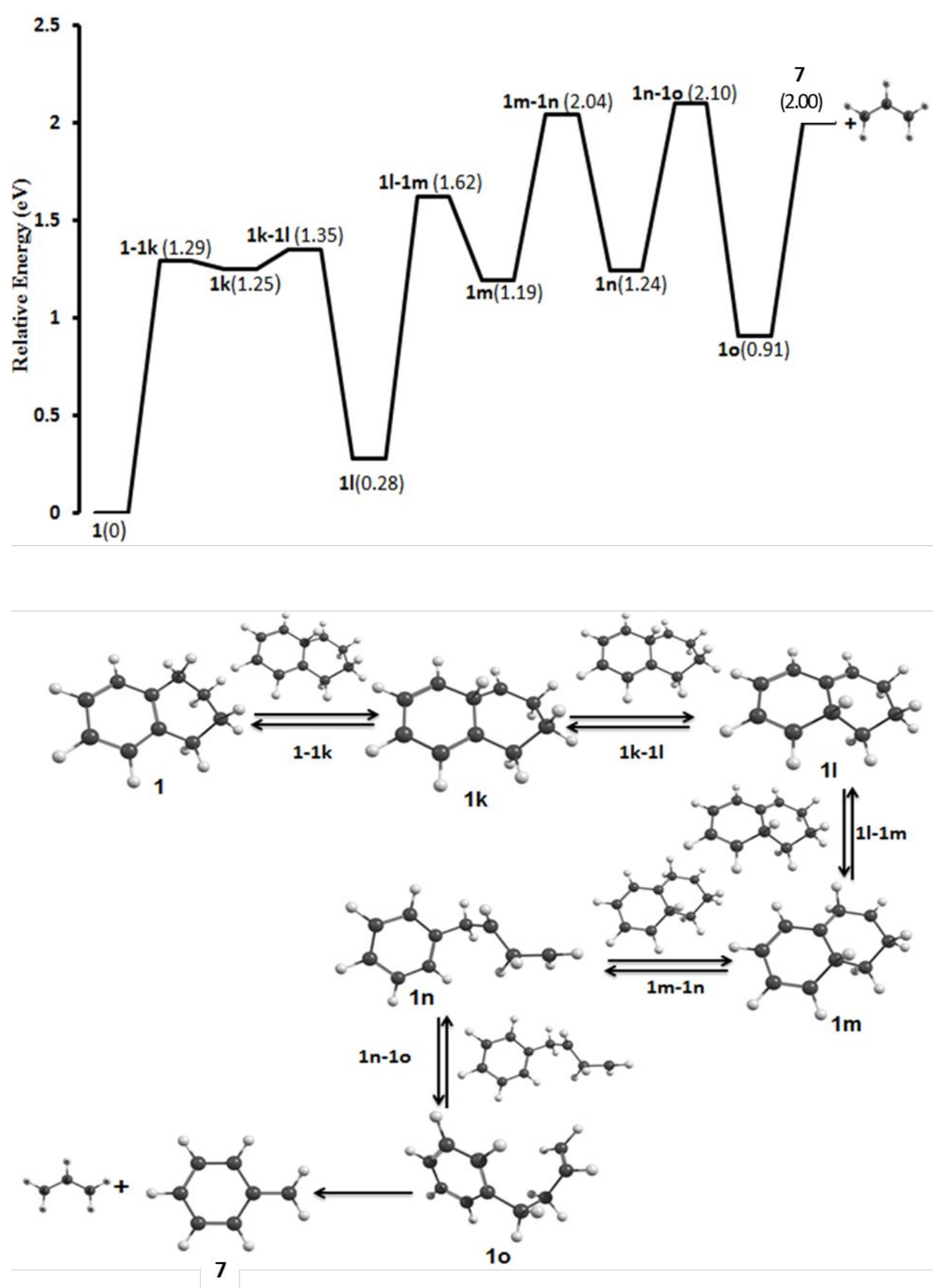
Figure 10. Potential energy surfaces for $\mathrm{C}_{3} \mathrm{H}_{5}{ }^{-}$-loss to form the benzyl cation 8 from ionized tetralin, computed at the B3LYP/6-31+G(d,p) level of theory. Relative energies $(e V)$ quoted in parentheses.

$\mathbf{H}^{\bullet}$ atom loss. Simple $\mathrm{H}^{\bullet}$-loss from ionized tetralin from the $\mathrm{sp}^{3}$ carbon atoms at the 1 or 4 position has a minimum energy requirement of $1.90 \mathrm{eV}$ computed at the B3LYP/6-31+G(d,p) level of theory. No reverse barrier was found from a relaxed potential energy surface scan at the B3LYP/6-31G(d) level of theory (Figure S3, Supporting Information). The energy required to remove one of the $\mathrm{H}^{\bullet}$ atoms from positions 2 or 3 raises to $2.56 \mathrm{eV}$, while from the unsaturated ring $\mathrm{H}$ loss was calculated to be 4.26 and $4.42 \mathrm{eV}$ (positions 5 and 6 respectively), similar to what one expects from ionized PAHs. ${ }^{40} \mathrm{H}^{\bullet}$ atom loss also likely occurs from the methylindane isomer, but the low abundance of the peak in the data made it unnecessary to include a second channel in the RRKM fitting. This latter $\mathrm{H}^{\bullet}$-loss reaction was calculated to have an energy requirement of $1.9 \mathrm{eV}$ at the B3LYP/6-31+G(d,p) level of theory.

$[\mathrm{M}-\mathbf{4 H}]^{\bullet+}$. The products of ionized naphthalene and two $\mathrm{H}_{2}$ molecules lie $0.93 \mathrm{eV}$ above the tetralin molecular ion. The TPES in this region does not exhibit any distinctive features that would suggest a suitable candidate electronic state, Fig. 1, but the OVGF calculations place two states in the dissociation window of the $[\mathrm{M}-4 \mathrm{H}]^{\bullet+}$ ion, $\mathrm{MO} 15$ and 16 (Table S1). MO 15 has the opposite lobes of the orbital on adjacent $\mathrm{C}_{2} \mathrm{H}_{4}$ units, so is particularly interesting from the point of view of being able to generate two $\mathrm{H}_{2}$ molecules (Fig. S4). This reaction would be worth exploring with an ultra-fast time-resolved spectroscopic technique. 


\section{CONCLUSIONS}

lonized tetralin, the simplest poly-hydrogenated $\mathrm{PAH}$, exhibits unimolecular reactions reminiscent to those of ionized 1,2-dihydronaphthalene and cyclohexane, which has been shown also to dissociation by loss of $\mathrm{H}^{\bullet}, \mathrm{CH}_{3}{ }^{\circ}, \mathrm{C}_{2} \mathrm{H}_{4}$ and $\mathrm{C}_{3} \mathrm{H}_{5}{ }^{\bullet}$ under electron- and photo-ionization. ${ }^{38}$ The molecular ion can undergo isomerization by $\mathrm{H}$-atom transfer and ring-opening reactions to yield $\mathrm{H}^{\bullet}, \mathrm{CH}_{3}{ }^{\circ}, \mathrm{C}_{2} \mathrm{H}_{4}$ and $\mathrm{C}_{3} \mathrm{H}_{5}{ }^{\bullet}$ neutral products, the latter producing the benzyl cation rather than the lower energy tropylium ion. In addition, the molecular ion isomerizes to the 1-methylindane ion structure over a barrier of $2.24 \mathrm{eV}$ (RRKM modeling) which then can go on to produce $\mathrm{CH}_{3}{ }^{\circ}$ and $\mathrm{C}_{2} \mathrm{H}_{4}$. Isomerization is dominated by facile $\mathrm{H}$-atom migration to the unsaturated ring carbons. In the end, ionized tetralin does not appear to undergo facile $\mathrm{H}$ atom or $\mathrm{H}_{2}$ molecule loss upon absorption of a photon, suggesting that PAHs may be sinks for $\mathrm{H}$ atoms in the ISM and not sources of $\mathrm{H}_{2}$. It will be of interest to explore larger hydrogenated PAHs to see if this is indeed a trend or unique to hydrogenated naphthalenes.

\section{ASSOCIATED CONTENT}

\section{Supporting Information}

The Supporting Information is available free of charge on the ACS Publications website at DOI: . The complete citation for reference 33, Table S1 comparing experimental and OVGF orbital IEs, Figure $\mathrm{S} 1$ with an expanded view of the $[\mathrm{M}-4 \mathrm{H}]+$ region of the iPEPICO breakdown curves, Figure $\mathrm{S} 2$ key intermediates in the azulene-containing $\mathrm{C}_{2} \mathrm{H}_{4}$ loss mechanism, Figure $\mathrm{S} 3$ a potential energy scan for $\mathrm{H}$ loss from ionized tetraline and Figure $\mathrm{S} 4$ molecular orbital pictures for the lowest 8 states of ionized tetralin (PDF).

\section{AUTHOR INFORMATION}

\section{Corresponding Author}

E-mail: pmmayer@uottawa.ca. Tel. 1-613-562-5800 ext 6038 


\section{ORCID}

Paul M. Mayer: 0000-0001-6112-4398

Jordy Bouwman: 0000-0002-3615-1703

\section{Notes}

The authors declare no competing financial interest.

\section{ACKNOWLEDGEMENTS}

P.M.M. thanks the Natural Sciences and Engineering Research Council of Canada for continued financial support. J.B. acknowledges the Netherlands Organisation for Scientific Research (Nederlandse Organisatie voor Wetenschappelijk Onderzoek, NWO) for a VIDI grant (grant number 723.016.006). The iPEPICO experiments were carried out at the VUV beamline of the Swiss Light Source at the Paul Scherrer Institute with the support of Drs. Andras Bödi and Patrick Hemberger. 


\section{References}

(1) PAHs and the universe: A symposium to celebrate the 25th anniversary of the PAH hypothesis; Joblin, C.; Tielens, A. G. G. M., Eds.; EAS Publications Series, 2011; Vol. 46.

(2) Castellanos, P.; Candian, A.; Andrews, H.; Tielens, A. G. G. M. Photoinduced polycyclic aromatic hydrocarbon dehydrogenation $A \& A$ 2018, 616, A167.

(3) Gould, R. J.; Salpeter, E. E. The interstellar abundance of the hydrogen molecule. I. Basic processes Astrophys. J. 1963, 138, 393-407.

(4) Cazaux, S.; Morisset, S.; Spaans, M.; Allouche, A. When sticking influences $\mathrm{H}_{2}$ formation A\&A 2011, 535, A27.

(5) Lemaire, J. L.; Vidali, G.; Baouche, S.; Chehrouri, M.; Chaabouni, H.; Mokrane, H. Competing mechanisms of molecular hydrogen formation in conditions relevant to the interstellar medium Astrophy. J. 2010, 725, L156-L160.

(6) Thrower, J. D.; Jørgensen, B.; Friis, E. E.; Baouche, S.; Mennella, V.; Luntz, A. C.; Andersen, M.; Hammer, B.; Hornekær, L. Experimental evidence for the formation of highly superhydrogenated polycyclic aromatic hydrocarbons through $\mathrm{H}$ atom addition and their catalytic role in $\mathrm{H}_{2}$ formation Astrophy. J. 2012, 752, 3 (6pp).

(7) Vala, M.; Szczepanski, J.; Oomens, J.; Steill, J. D. $\mathrm{H}_{2}$ ejection from polycyclic aromatic hydrocarbons: Infrared multiphoton dissociation study of protonated 1,2-dihydronaphthalene J. Am. Chem. Soc. 2009, 131, 5784-5791.

(8) Rauls, E.; Hornekær, L. Catalyzed routes to molecular hydrogen formation and hydrogen addition reactions on neutral polycyclic aromatic hydrocarbons under interstellar conditions Astrophy. J. 2008, 679, 531-536.

(9) Bauschlicher, J. C. W. The reaction of polycyclic aromatic hydrocarbon cations with hydrogen atoms: The astrophysical implications Astrophy. J. 1998, 509, L125-L127.

(10) Hirama, M.; Tokosumi, T.; Ishida, T.; Aihara, J.-I. Possible molecular hydrogen formation mediated by the inner and outer carbon atoms of typical PAH cations Chem. Phys. 2004, 305, 307-316.

(11) Cassam-Chenaï, P.; Pauzat, F.; Ellinger, Y. Is stripping of polycyclic aromatic hydrocarbons a route to molecular hydrogen? AIP Conf. Proceed. 1994, 312, 543-547.

(12) Kapinus, V. A. Photophysical properties of protonated aromatic hydrocarbons, California Institute of Technology, 2005.

(13) Reitsma, G.; Boschman, L.; J. Deuzeman, M.; Gonzalez-Magana, O.; Hoekstra, S.; Cazaux, S.; Hoekstra, R.; Schlathölter, T. Deexcitation dynamics of superhydrogenated polycyclic aromatic hydrocarbon cations after soft-x-ray absorption Phys. Rev. Lett. 2014, 113, 053002.

(14) Wolf, M.; Kiefer, H. V.; Langeland, J.; Andersen, L. H.; Zettergren, H.; Schmidt, H. T.; Cederquist, H.; Stockett, M. H. Photo-stability of super-hydrogenated PAHs Astrophy. J. 2016, 832, 24.

(15) Wolf, M.; Giacomozzi, L.; Gatchell, M.; de Ruette, N.; Stockett, M. H.; Schmidt, H. T.; Cederquist, H.; Zettergren, H. Hydrogenated pyrene: Statistical single-carbon loss below the knockout threshold Euro. Phys. J. D 2016, 70, 85.

(16) Gatchell, M.; Stockett, M. H.; de Ruette, N.; Chen, T.; Giacomozzi, L.; Nascimento, R. F.; Wolf, M.; Anderson, E. K.; Delaunay, R.; Vizcaino, V. et. al. Failure of hydrogenation in protecting polycyclic aromatic hydrocarbons from fragmentation Phys. Rev. A 2015, 92, 050702.

(17) Rapacioli, M.; Cazaux, S.; Foley, N.; Simon, A.; Hoekstra, R.; Schlathölter, T. Atomic hydrogen interactions with gas-phase coronene cations: Hydrogenation versus fragmentation Phys. Chem. Chem. Phys. 2018, 20, 22427-22438.

(18) Cazaux, S.; Arribard, Y.; Egorov, D.; Palotás, J.; Hoekstra, R.; Berden, G.; Oomens, J.; Schlathölter, T. The sequence of coronene hydrogenation revealed by gas-phase IR spectroscopy Astrophy. J. 2019, 875, 27. 
(19) Cazaux, S.; Boschman, L.; Rougeau, N.; Reitsma, G.; Hoekstra, R.; Teillet-Billy, D.; Morisset, S.; Spaans, M.; Schlathölter, T. The sequence to hydrogenate coronene cations: A journey guided by magic numbers Sci. Rep. 2016, 6, 19835.

(20) West, B.; Joblin, C.; Blanchet, V.; Bodi, A.; Sztáray, B.; Mayer, P. M. Dynamics of hydrogen and methyl radical loss from ionized dihydro-polycyclic aromatic hydrocarbons: A tandem mass spectrometry and imaging photoelectron-photoion coincidence (iPEPICO) study of dihydronaphthalene and dihydrophenanthrene J. Phys. Chem. A 2014, 118, 1807-1816.

(21) Wang, H.; Gerken, W. J.; Wang, W.; Oehlschlaeger, M. A. Experimental study of the hightemperature autoignition of tetralin Energy \& Fuels 2013, 27, 5483-5487.

(22) Pitz, W. J.; Mueller, C. J. Recent progress in the development of diesel surrogate fuels Prog. Energy Combust. Sci. 2011, 37, 330-350.

(23) Tsang, W.; Cui, J. P. Homogeneous gas-phase decyclization of tetralin and benzocyclobutene J. Am. Chem. Soc. 1990, 112, 1665-1671.

(24) Li, C.; Suzuki, K. Resources, properties and utilization of tar Resour. Conserv. Recycl. 2010, $54,905-915$.

(25) Blum, P.; Sagner, A.; Tiehm, A.; Martus, P.; Wendel, T.; Grathwohl, P. Importance of heterocylic aromatic compounds in monitored natural attenuation for coal tar contaminated aquifers: $A$ review J. Contam. Hydrol. 2011, 126, 181-194.

(26) Wang, Y.; Shah, N.; Huggins, F. E.; Huffman, G. P. Hydrogen production by catalytic dehydrogenation of tetralin and decalin over stacked cone carbon nanotube-supported pt catalysts Energy \& Fuels 2006, 20, 2612-2615.

(27) Vaikkinen, A.; Kauppila, T. J.; Kostiainen, R. Charge exchange reaction in dopant-assisted atmospheric pressure chemical ionization and atmospheric pressure photoionization J. Am. Soc. Mass Spectrom. 2016, 27 1291-1300.

(28) Bodi, A.; Sztaray, B.; Baer, T.; Johnson, M.; Gerber, T. Data acquisition schemes for continuous two-particle time-of-flight coincidence experiments Rev. Sci. Instrum. 2007, 78, 084102.

(29) Sztáray, B.; Bodi, A.; Baer, T. Modeling unimolecular reactions in photoelectron photoion coincidence experiments J. Mass Spectrom. 2010, 45, 1233-1245.

(30) Bodi, A.; Hemberger, P.; Gerber, T.; Sztáray, B. A new double imaging velocity focusing coincidence experiment: i²PEPICO. Rev. Sci. Instrum. 2012, 83, 083105.

(31) Hemberger, P.; Custodis, V. B. F.; Bodi, A.; Gerber, T.; Bokhoven, J. A. v. Understanding the mechanism of catalytic fast pyrolysis by unveiling reactive intermediates in heterogeneous catalysis Nat. Commun. 2017, 8, 15946.

(32) Sztáray, B.; Baer, T. Suppression of hot electrons in threshold photoelectron photoion coincidence spectroscopy using velocity focusing optics Rev. Sci. Instr. 2003, 74, 3763-3768.

(33) Frisch, M. J.; Trucks, G. W.; Schlegel, H. B.; Scuseria, G. E.; Robb, M. A.; Cheeseman, J. R.; Scalmani, G.; Barone, V.; Petersson, G. A.; Nakatsuji, H. et. al., Gaussian 16 rev. B.01, Wallingford, CT, 2016.

(34) Barone, V.; Bloino, J.; Biczysko, M.; Santoro, F. Fully integrated approach to compute vibrationally resolved optical spectra: From small molecules to macrosystems J. Chem. Theory Comput. 2009, 5, 540-554.

(35) Baer, T.; Hase, W. L., Unimolecular reaction dynamics, theory and experiments. Oxford University Press: New York, 1996

(36) Baer, T.; Mayer, P. M. Statistical RRKM/QET calculations in mass spectrometry J. Am. Soc. Mass Spectrom. 1997, 8, 103-115.

(37) Beyer, T.; Swinehart, D. R. Number of multiply-restricted partitions [a1] (algorithm 448) ACM Commun. 1973, 16, 379. 
(38) Webbook, N. C., NIST standard reference database number 69. ed; National Institute of Standards and Technology: Gaithersburg, MD, 2005

(39) Bouwman, J.; de Haas, A. J.; Oomens, J. Spectroscopic evidence for the formation of pentalene $^{+}$in the dissociative ionization of naphthalene Chem. Commun. 2016, 52, 2636-2638.

(40) West, B.; Rodriguez Castillo, S.; Sit, A.; Mohamad, S.; Lowe, B.; Joblin, C.; Bodi, A.; Mayer, P. M. Unimolecular reaction energies for polycyclic aromatic hydrocarbon ions Phys. Chem. Chem. Phys. 2018, 20, 7195-7205.

(41) Solano, E. A.; Mayer, P. M. A complete map of the ion chemistry of the naphthalene radical cation? DFT and RRKM modeling of a complex potential energy surface J. Chem. Phys. 2015, 143, 104305. 


\section{TOC Graphic}

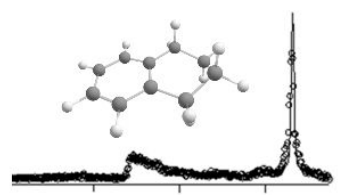

